\title{
¿Por qué y para qué filosofar en América Latina?
}

Tal vez para algunos de los que se dedican a la actividad filosófica constituyan preguntas pueriles ¿por qué y para qué filosofar en América Latina? (Guadarrama, 1990). Sin embargo, los que ignoren o menosprecien tal cuestionamiento constituirán siempre una minoría. Se puede afirmar que la mayor parte de los que cultivan con verdadero amor la filosofía en "Nuestra América", no solo se las han planteado más de una vez, sino que continúan reformulándolas desde diversos ángulos constantemente; pues, aunque hayan encontrado alguna que otra respuesta, por lo general no se sentirán satisfechos.

Alguien pudiera argumentar que muchos de los más reconocidos filósofos no dejaron explícitamente plasmada su preocupación por estos problemas y simplemente hacían filosofía sin reflexionar demasiado en el porqué y el para qué lo hacían. Especialmente ese último interrogante en ocasiones es considerado como algo pretencioso y escapa de los marcos del estricto rigor filosófico para adentrarse en otras esferas.

En verdad, a nuestro juicio, no ha habido filósofo alguno, digno de ser considerado como tal, que de una forma u otra, consciente plenamente o de manera espontánea, no se haya sentido inquieto constantemente por dicho 
problema. Sus propuestas de soluciones quizás no hayan trascendido los monólogos íntimos de su conciencia y por tanto no permanezcan grabadas para la posteridad. Pero no cabe duda de que su formulación ha estado presente en todos y en cada uno de estos pensadores.

No todas las épocas históricas ni las distintas regiones en que se ha desarrollado la filosofía han sido propicias para que aflore con mayor claridad y fuerza esta problemática. Tampoco la atención otorgada a ambas preguntas ha sido siempre similar. En los albores de la filosofía y en general en la antigüedad hubo más interés por el por qué en tanto que el para qué se subordinó a las respuestas ofrecidas a la primera cuestión.

Es muy probable que durante la larga Edad Media, aun cuando se mantuviese viva en muchos talentos la preocupación por ofrecer algunos aportes o modificaciones sustanciales a las concepciones estatuidas por la escolástica al respecto, no se hubiese presentado esta cuestión como principal para el quehacer filosófico de la época.

Los momentos dé grandes convulsiones sociales propician que se incrementen las preocupaciones por este aspecto. De ahí que tanto en la Ilustración europea como en la latinoamericana aparezcan más elementos para enjuiciar los "porqué y para qué" se desarrollaba por entonces la filosofía.

Al estudiar a los pensadores latinoamericanos de la segunda mitad del siglo XVIII e inicios del XIX, aparecen con mayor frecuencia elementos que indican una reflexión creciente sobre los requerimientos y funciones de la filosofía, pues los cambios sociopolíticos que se avecinaban y las transformaciones que se producían en el mundo de la ciencia y de la técnica demandaban un enriquecimiento del arsenal cosmovisivo de quienes emprenderían la emancipación política y espiritual futura, y también mayor claridad en la utilidad de la labor filosófica.

En la segunda mitad del XIX y con el predominio del positivismo sui generis (Guadarrama, 2011, pp. 125-149) en la mayor parte de las tierras de América, la inquietud por tales preguntas no se manifestó de forma constante. Al parecer dejó de ser objeto de interés principal, pues se presuponía como inherente a toda dedicación por la filosofía y la ciencia haber definido ya una posición pragmática al respecto y no era necesario malgastar el tiempo en viejas especulaciones que no se correspondían con las exigencias de los nuevos tiempos. Sin embargo, siempre emergía alguna que otra 
valoración sobre el tema, aunque nunca con la intensidad que se presentaría en el siglo $\mathrm{xx}$.

A partir del momento en que toma mayor auge el problema de la existencia de la filosofía latinoamericana, se acrecentó el interés por el por qué y para qué filosofar. No se debe desviar la atención hacia tal debate, que para muchos ha sido superado ya, pero que realmente en frecuentes ocasiones reverdece como indicando que no ha podido ser sepultado definitivamente. Lo cierto es que, partidarios o no de la existencia de la filosofía latinoamericana, en el presente, todo intelectual dedicado a la vida filosófica se ve obligado a definirse entre las interrogantes que motivaron el presente análisis.

Desde hace algún tiempo se ha podido apreciar la preocupación creciente sobre el tema del porqué y para qué filosofar en América Latina por parte de colegas de distintos países y de diferentes posiciones filosóficas. En francos diálogos, no obstante expresarse la diversidad de criterios al respecto (Sierra, 2002, p.40) ${ }^{48}$ se ponen de manifiesto ciertas similitudes que nos han conducido a la presente reflexión y a concluir provisionalmente que al menos pueden delimitarse tres posiciones fundamentales. En algunas de estas confluyen a veces intelectuales, cuyos puntos de partida y los fundamentos teórico-metodológicos en los que se asientan sus respectivas concepciones filosóficas son marcadamente diferentes, pero coinciden en gran medida en las respuestas que ofrecen a dichas preguntas.

48 "Aunque debemos afirmar que no existe una filosofía latinoamericana simplemente porque aún no ha hecho ningún aporte importante y colectivo a esta disciplina, tenemos que reconocer, sin embargo, que la práctica filosófica ha logrado entre nosotros un estadio de madurez, podríamos decir de mayoría de edad, en el manejo de las cuestiones filosóficas. Es sobre todo ya una práctica corriente en nuestra actividad cultural: tanto por el volumen como por la calidad puede decirse que es una actividad normal esa de hacer filosofía, habiéndose logrado sobre todo el profesionalismo necesario para un verdadero despegue filosófico. Pero lo más notorio de esa normalización de la práctica filosófica, es que nuestros filósofos más representativos han dejado de pensar en hacer filosofía latinoamericana para hacer simplemente filosofía, lo cual también es una condición para que en el futuro pueda aparecer un pensamiento filosófico que represente una verdadera creación dentro de la corriente occidental de la cultura. El filósofo latinoamericano lo que está haciendo es apropiarse de los grandes temas de las filosofía para pensarlos desde la historia y las categorías propias de esta disciplina." Sierra Mejía, Rubén. Ensayos impopulares, Editorial Universidad de Caldas, Manizales, 2002, p. 40. 
Dentro de tal amalgama de criterios se destacan las siguientes tendencias: La primera se puede denominar hermenéutica o exegética: se caracteriza por concebir el por qué filosofar como una preocupación necesaria, universal e inherente a todo ser humano sobre la esencia del mundo, su lugar en él, y demás. En cuanto al para qué, se limitan en muchos casos a la consideración de que dichas explicaciones sirven satisfacer la sed constante de la sabiduría humana. No es menos cierto que otorgan también importancia a las funciones educativa humanística (Rabossi, 1984, p. 4) ${ }^{49}$ que desempeña la filosofía, pero en sentido general van más allá de concederle algún mérito en este plano del enriquecimiento espiritual exclusivamente (Gracia y Frondizi, 1981, p.21). ${ }^{50}$

Los seguidores de esta tendencia, por lo regular, son defensores de un pluralismo, un idealismo contemplativo y de un universalismo abstracto y extrapolador de la filosofía a las más sutiles trascendencias. Tratan de limitar las cuestiones filosóficas bien a las que clásicamente han sido señaladas desde la antigüedad hasta nuestros días, bien a alguna otra que

49 "Aprender a filosofar -es decir- aprender a realizar la actividad teórica que es propia del filósofo- exige internalizar los mecanismos discursivos utilizados por los grandes filósofos. En este sentido aprender a filosofar es parecido, en gran medida, a aprender un arte. Pero no es solo eso. Aprender a filosofar involucra además, aprender a utilizar técnicas adecuadas de análisis y sistematización y acceder a la historia de la filosofía 'como historia del uso la razón' y consiguientemente, como objeto propio para el ejercicio filosófico." Rabossi, Eduardo. "Enseñar filosofía y aprender a filosofar". En Cuadernos de Filosofía y Letras No. 3-4, Universidad de los Andes, Bogotá, julio-diciembre de 1984, VIII, p. 4.

50 Los representantes de la filosofía analítica, que se ubican por lo regular dentro de esa tendencia, se esfuerzan por criticar al marxismo considerando que este no le otorga la mayor atención a la actividad teórica. Así por ejemplo Jorge Gracia sostiene: 'lo mismo ocurre con el marxismo, salvo contados casos excepcionales. Es la filosofía política más difundida y. embargo, no hay filósofos marxistas de relieve. Para los marxistas latinoamericanos se trate una doctrina que hay que estudiar, difundir y defender, la indagación crítica pasa a un segundo plano. Tanto en el tomismo como en el marxismo un tono proselitista empaña la calidad teórica". Gracia, Jorge y Frondizi, R. E! hombre y las valores en la filosofía latinoamericana del siglo XX. Fondo de Cultura Económica, México, 1981, p. 21. De tal modo se ignora la vasta actividad teórica de los marxistas latinoamericanos --y por qué no, también de tomistas-, que se puede apreciar en las últimas décadas, sin que la misma signifique abandono de la actividad sociopolítica práctica de la mayoría de los intelectuales marxistas como tal vez fuera de mayor agrado para estos filósofos adeptos a la "pura" teoría. 
se derive directamente de ella, pero evitan por todos los medios que estas puedan tener alguna implicación directa con la política (Cruz Vélez, 1989, p. 161), ${ }^{51}$ o con la realidad concreta de su respectivo país o de la región. Aun cuando durante los años de represión de la democracia ha afectado notablemente a todas las manifestaciones de la cultura de la mayor parte de los países latinoamericanos y que aún hoy día, desgraciadamente, mantiene algunos exponentes, y se aprecie la huella de la falta de libertad expresiva entre muchos intelectuales progresistas que han tenido que refugiarse en las disquisiciones más abstractas como único terreno seguro que evita posibles represalias.

Con frecuencia, en diálogos privados, gran parte de estos filósofos confiesan ideas, preocupaciones y posiciones que serían incapaces de divulgar o de plasmar por escrito en sus obras. Algunas de ellas contradicen abiertamente las sostenidas en aquellas $y$, aunque resulte necesario reconocer la evolución lógica del pensamiento de todo ser humano, estas manifestaciones no son más que síntomas de la constante presión que han sentido sobre sus hombros a la hora de expresar sus opiniones, especialmente sobre el para qué filosofar en América Latina. Ante tales actitudes no cabe más que el respeto y la condescendencia, aun cuando presione la insatisfacción constante que impulsa a todo pensamiento revolucionario.

En otros casos, desgraciadamente, hay que reconocer que en un gran número, esa postura universalista abstracta no es más que expresión consecuente de su actitud ideológica de indiferencia ante los males que afligen a los pueblos latinoamericanos. Algunos de estos intelectuales, bien por su procedencia social o por sus vínculos extraacadémicos, pertenecen a las elites de poder en sus respectivos países y mantienen compromisos muy

51 "Cuando el filósofo interesado en la realidad sociopolítica deja su profesión propia, que es la de construir modelos ideales para esa realidad, y se mete a manejarla como el político ocurre casi siempre lo mismo que al prisionero de la alegoría de la caverna que, después abandonarla para ascender a la región de la luz, regresa a ella para liberar a sus antiguos compañeros de prisión. Desacostumbrado a la oscuridad, la torpeza de sus movimientos y la incapacidad de orientarse en el nuevo elemento solo provocarán entre ellos burla, improperios. E irritados por el intento liberador de cambiarles las opiniones imperantes la caverna por las ideas y los ideales traídos de 'arriba', los cavernícolas terminarán por darle muerte, como le ocurrió a Sócrates con los atenienses." Cruz Vélez, D. El mito del rey filósofo. Planeta Colombiana Editorial, Bogotá, 1989, p. 161. 
serios que su labor filosófica no debe en ninguna forma afectar. Incluso existen hasta quienes no conciben la filosofía como una actitud de búsqueda desinteresada materialmente por la consecución de formulaciones teóricas ante las grandes incógnitas humanas, sino más bien se dedican a la filosofía como una profesión lucrativa más, que les proporciona un prestigioso status socioeconómico y les permite sobrevivir decorosamente en medio de las dificultades financieras, entre otras más graves aún, que afectan a nuestros países.

En lo relacionado a su formación académica, por lo regular este tipo de intelectuales latinoamericanos la han desarrollado o completado en prestigiosas universidades europeas o norteamericanas donde establecieron vínculos muy sólidos con la corriente filosófica en boga allí o con el profesor de renombre con el cual tuvieron mayor conexión, y este hecho ha marcado el rumbo definitivo de su orientación. Han regresado a su tierra trayendo las mismas preocupaciones intelectuales de sus respectivos tutores, se han aferrado al planteamiento de la validez universal de los mismos y no le incorporan una pizca de terrenalidad latinoamericana, por considerarlo como vulgarizador simplificador de la filosofía. Desgraciadamente esto ha ocurrido también en ocasiones entre algunos intelectuales marxistas, cuyas actitudes han propiciado el fundamento razonable de algunas críticas provenientes del antimarxismo (Guadarrama, 2015). De tal modo se han ido convirtiendo en representantes o continuadores de tal o cual escuela de pensamiento y disfrutan del prestigio de haber traído la última moda de que se piensa en los "grandes centros de la filosofía mundial" y en sentido son víctimas inconscientes del neocolonialismo cultural.

Este tipo de filósofo latinoamericano se caracteriza por dirigir casi siempre su mirada al cielo de las grandes abstracciones, que muchas veces expresa en el idioma extranjero de origen, o mediante creación de neologismos indescifrables en algunos casos para los humanos de mediana cultura filosófica. Naturalmente su mensaje no está dirigido a la "plebe", argumentarán, sino a un círculo cerrado de discípulos o seguidores de la misma escuela de pensamiento, que de igual forma podrán transmitir en la misma longitud de onda tal logomaquia.

A esta tendencia la llamamos hermenéutica o exegética, aunque en ocasiones pudiera también llamársele filológica, pues se limita a la interpretación de lo que quiso decir tal o cual pensador al formular alguna idea o 
nueva categoría. A partir de este tipo de análisis se establecen discusiones con otros estudiosos del filósofo o del problema en cuestión, y así se reducen las respuestas a las preguntas básica que se han indicado a lo siguiente: ¿por qué filosofar?, porque es necesario esclarecer e interpretar adecuadamente lo planteado por tal filósofo; y ¿para qué?, para acrecentar la sabiduría, que en definitiva es el núcleo alrededor del cual gira toda la actividad filosófica.

La segunda tendencia puede ser denominada filosofía latinoamericana: a diferencia de la anterior, se ha preocupado más por la procedencia del sujeto que elabora la filosofía, el terreno de donde parten sus reflexiones y la efectividad que puedan tener para el ámbito latinoamericano. En lugar de dejarse arrastrar por el universalismo abstracto y el pluralismo de la primera tendencia, esta posición se caracteriza por insistir más en la orientación hacia lo continental y lo histórico (Martí, 1984, pp. 9-10). ${ }^{52}$ Esta tendencia ha tenido diversas manifestaciones en correspondencia con los diferentes puntos de partida filosóficos de sus distintos representantes, por lo que igual que la primera, no constituye un grupo homogéneo, pero todos coinciden en la necesidad de elaborar respuestas al porqué y para qué filosofar, siempre desde una perspectiva latinoamericana. Dentro de los que en los últimos tiempos han asumido con mayor vehemencia esta posición se destacan las distintas formas que adopta la conocida filosofía latinoamericana de la liberación.

A la hora de hurgar en las causas que determinan una actitud diferente por parte de los seguidores de esta segunda tendencia, se aprecia un compromiso ideológico mayor con las aspiraciones de los sectores populares

52 "Muchos filósofos creen que la filosofía trata de problemas universales y que un estudio histórico de estos problemas, aunque interesa, es no sólo superfluo sino que distrae de la verdadera labor filosófica, sea esta la de buscar verdades eternas, la de resolver problemas, o la de disolver seudoproblemas filosóficos. Tan prevaleciente es este punto de vista que ha alcanzado el rango de dogma y ha llegado a saturar nuestras presunciones sobre la historia de la filosofía, a tal punto que muchos historiadores creen divisar temas universales en esta historia. Otros historiadores de la filosofía, entre ellos los llamados historicistas, han tomado una postura defensiva y han declarado que el universalismo filosófico es un error, y que la filosofía no se puede librar de su trasfondo histórico. Mi propia posición en favor del historicismo se ha basado en la historicidad del lenguaje conceptual." Martí, Oscar. "Historia y filosofía de nuestra América”. En Prometeo. No. 1. Revista Latinoamericana de Filosofía, Guadalajara, septiembre-diciembre 1984. pp. 9-10. 
(Magallón, 1985, p. 15). ${ }^{53}$ Han asumido la tarea filosófica conscientes de la necesidad de producir un viraje en la actividad filosófica tradicional, con proyecciones nuevas que aspiran a dejar atrás el estéril academicismo de los hermenéuticos, y orientarse hacia problemas y temas que ante todo son de mayor urgencia para los latinoamericanos.

La mayoría de los defensores de la filosofía latinoamericana coinciden en ofrecer respuestas a las preguntas formuladas del siguiente modo: ¿por qué filosofar?, porque los problemas concretos del ser latinoamericano lo exigen y hasta el presente las filosofías importadas no dan respuesta adecuada a tales demandas (Dussel, 1985, p. 24); ${ }^{54}$ y ¿para qué filosofar?, para encontrar esas respuestas y vías de solución que modifiquen progresivamente la situación de nuestros pueblos. Muchas de las conclusiones a que arriban no pretenden ser solamente válidas para esta región, para todos los pueblos del llamado Tercer Mundo. En tal forma manifiestan algunos contactos con la universalidad concreta y real, pero no alcanzan por lo general a encontrarla plena explicación y en algunos casos cuando se acercan a ella no ofrecen la indicación adecuada para hallar los caminos de su efectiva superación.

Resultan muy positivos gran parte de los enjuiciamientos que efectúan respecto a los valores que encierra la cultura y especialmente el pensamiento filosófico latinoamericano. Son acertadas muchas de sus críticas al

53 "La filosofía de la liberación no puede ser posterior a la lucha por la libertad de nuestras naciones, sino más bien previa, para que críticamente y auxiliada por las ciencias sociales y las relaciones de la praxis social se constituya en una ideología que tendrá como objetivo la liberación del dominio imperial, ejercido desde dentro por los testaferros de cada país, servidores incondicionales del imperialismo, y desde fuera con las amenazas directas de tipo violento hasta las sofisticadas y ejercidas de corte económico y de financiamiento. Es así que la filosofía de la liberación debe y es una acción comprometida con los compromisos sociales, culturales, políticos y económicos de un determinado momento histórico de América Latina; por tanto es una filosofía que está comprometida y milita como parte de la ideología de la lucha revolucionaria al lado del ejercicio de los ideales revolucionarios de estos pueblos oprimidos." Magallón, Mario: "Filosofía de circunstancia" en Prometeo. No.3. Guadalajara, mayo-agosto de 1985, p. 15.

54 "Contra la ontología clásica del centro, desde Hegel hasta Marcuse, para nombrar lo más lúcido de Europa, se levanta una filosofía de la liberación de la periferia, de los oprimidos, la sombra que la luz del ser no ha podido iluminar." Dussel, Enrique: La filosofía de la liberación. Ediciones La Aurora, Buenos Aires, 1985, p. 24. 
imperialismo cultural y al eurocentrismo (Pla, 1989) ${ }^{55}$ que ha caracterizado por mucho tiempo a la filosofía, y que ha sido aceptado plácidamente también por muchos intelectuales latinoamericanos, pertenecientes a la primera tendencia. Dignas de atención han sido sus revelaciones respecto a la originalidad y autenticidad de gran parte de las ideas filosóficas de los más prestigiosos representantes de nuestro pensamiento. Valientes han sido sus críticas a los factores que determinan la dependencia y el subdesarrollo que han caracterizado a nuestras economías deformadas Si se realizara un balance preliminar de lo que ha aportado esta nueva corriente de pensamiento a la cultura filosófica latinoamericana, de seguro el saldo será favorable y la historiografía futura de la filosofía en América Latina tendrá que dedicarle una merecida atención (Guadarrama, 1986b, pp. 25-34).

Sin embargo, el enjuiciamiento crítico acertado de esta tendencia se verá precisado a valorar que, en algunos momentos, en ella se impuso un enfoque unilateral que, sin llegar a cercenar por completo el tronco universal aglutinador de todos los conductos que comunican cada rama, cada hoja y cada flor del árbol de la filosofía con su savia nutriente; al prestar exagerada atención a sus raíces terrenales, subestimó por momentos otros factores exógenos ambientales, especialmente los rayos solares que vivifican diariamente con la claridad de la ciencia a otros tantos árboles similares en otras latitudes.

Puede que se haya ignorado que la filosofía es como una tupida y extensa selva, en la cual al adentrarnos en ella nos impresionan los árboles más cercanos por su belleza, que la proximidad nos permite contemplar y una vez escrutados se incorporan a nuestro yo, como otras tantas vivencias anteriores que han dejado sus huellas en nuestra conciencia y sentimos cierta sensación de pertenencia e identificación. Pero al otear la profundidad del entretejido de los árboles y ramas más lejanos se nos hace oscuro y ajeno

55 El tema de la crítica al eurocentrismo ha sido uno de los que ha centrado la atención de la filosofía de la liberación en sus críticas al marxismo, al considerársele una variante más de aquel. Una argumentación del carácter infundado de tal visión del marxismo puede apreciarse en Plá León, Rafael: "Marxismo, ¿eurocentrismo o universalidad'?" Ponencia presentada al II Simposio sobre Pensamiento Filosófico Latinoamericano de la Universidad Central de Las Villas. Santa Clara, noviembre de 1989. 
aquello que posteriormente puede ser también nuestro si continuamos la marcha con paso firme y decidido.

Algunos partidarios de la filosofía latinoamericana han querido redescubrir la filosofía y conformar nuevos sistemas filosóficos en el círculo visual de la terrenalidad latinoamericana, rompiendo con los instrumentos y las elaboraciones teóricas, categorías, entre otras, que anteriormente nos proporcionaron las escuelas de pensamiento orientales y europeas, entre las cuales destacan el marxismo (Ardiles, 1988, p. 167). ${ }^{56} \mathrm{El}$ intento ha sido en vano, pues siempre se ha tenido que recurrir de alguna manera a ese arsenal, aun cuando también se le incorporen nuevas armas (Roig, 1984, p. 58). ${ }^{57}$

La visión regionalista de la filosofía no solo en América Latina, sino en cualquier parte del mundo donde se ha manifestado, lejos de contribuir al verdadero enriquecimiento de la cultura filosófica, como se ha pretendido, en su lugar ha afectado la acertada comprensión y valoración del carácter histórico universal de la filosofía.

Por suerte, en los últimos tiempos son cada vez menos los identificados con esta posición tan estrecha y se ven precisados a coincidir con los sostenedores de la concepción acertada sobre la universalidad de la filosofía. Sin embargo, con frecuencia emergen reticencias que denotan insistir en la condicionalidad del sujeto del filosofar latinoamericano y que no son más que otro síntoma de disconformidad con el universalismo abstracto. En ese sentido tales criterios son comprensibles. Pero ambas posiciones, en definitiva, no obstante la manera diferente de dar respuesta a las preguntas inicialmente formuladas, no llegan a la explicación acertada del papel, la esencia y las funciones de la filosofía y su expresión en el ámbito latinoamericano.

56 "Se considera así, que, por ejemplo, el marxismo no es ya, como pretendió la Guerra Fría, el gran enemigo de los valores de la civilización occidental, sino la última artimaña del Imperio para mantenernos enredados en teorías distractivas." Osvaldo Ardiles: El exilio de la razón. Sils-María, Córdoba, Argentina, 1988, p. 167.

57 Otro de los más prestigiosos fundadores de esa corriente de pensamiento tan heterogénea, conocida como filosofía de la liberación, fue Arturo Andrés Roig, quien se distanció de ella, planteaba: “...en lo que podríamos llamar el 'ala derecha' del movimiento, fue entendida la 'filosofía de la liberación' como una alternativa entre el individualismo liberal del capitalismo y el marxismo, el cual era acusado de 'colectivismo anticristiano'.". Roig. Arturo Andrés: "Cuatro tomas de posición". En Nuestra América. No. 11, mayo-agosto de 1984, UNAM, México, p. 58. 
La segunda tendencia indiscutiblemente representa un grado mayor de aproximación a la verdad que se desprende de las respuestas al porqué y para qué filosofar en América latina; de aquí las mayores o menores coincidencias por parte de algunos de sus representantes, últimamente, con las posiciones del marxismo.

La recepción del marxismo por los voceros de la filosofía de la liberación constituye un tema de extraordinario interés, pues no solo se aprecia una muy disímil actitud entre sus diferentes tendencias, sino también cambios sustanciales dentro de una misma en distintos períodos. Así por ejemplo, Enrique Dussel, una de sus figuras principales, ha reconocido que "en su origen argentino, y por influencia del populismo peronista la cuestión de Marx fue mal planteada por la generación de filósofos de la liberación. Esto nos valió merecidas críticas. Algunos que terminaron por volcarse a la derecha y otros a permanecer en el populismo, colocaban a la filosofía de la liberación como alternativa al pensamiento de Marx. Debo confesar que lo conocíamos mal. No lo habíamos trabajado como a otros pensadores"(Dussel, 1983, p. 93). A partir de dicho reconocimiento comenzó un proceso de asimilación y de estudio de la obra de Marx, pero a su vez de diferenciación

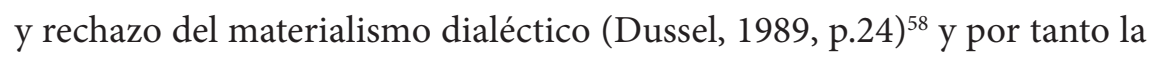
exclusiva aceptación del materialismo histórico.

En algunos de sus libros Dussel le dedicaría cada vez mayor atención al marxismo y ha llegado a plantear que "la filosofía de la liberación tiene mucho que aprender de Marx" (Dussel, 1988b, p. 310). Es evidente que ha profundizado considerablemente en el conocimiento de las dimensiones de su pensamiento y se ha producido un acercamiento real al marxismo, al plantear la necesidad de "comprender el estatus científico del programa de investigación de Marx" (Dussel, 2001, p. 297); aunque se le objete que "intenta hacer de Marx un dusseliano" (Schutte, 1987, p. 28) y que "la filosofía de la liberación tal como la desarrolla Dussel, intenta reemplazar al marxismo"(Schutte, 1987, p. 27). En verdad son muchos los seguidores de

58 'El marxismo -cuando se define como 'materialismo dialéctico' de tipo dogmático o staliniano- puede ser una ideología de dominación. Liberarlo en favor- de una conciencia siempre crítica es situarlo como Filosofía de la Liberación." Dussel, Enrique "Retos actuales de la filosofía de la liberación". En Libertacao. No. 1, Porto Alegre Año 1, 1989, p. 24. 
esta corriente de pensamiento que reconocen abiertamente, que el marxismo es una de las fuentes principales del pensamiento liberador en la filosofía (Hernández, 1987, p. 5) aunque subsista la tendencia opuesta que se niega a tal reconocimiento.

En el caso de Leopoldo Zea, que es uno de los antecedentes y pilares a su vez de la filosofía de la liberación, también se ha operado un proceso evolutivo (Guadarrama, 1987, pp. 131-149), que presupone un cambio de actitud ante el marxismo, aunque sea válido el juicio de que "Zea no es marxista ni hay nada en su discurso que permita afirmar tal orientación teórica"(Cerutti, 1986, p. 55), lo cual no impide que se aprecie en él un notable cambio de actitud favorable al socialismo y al marxismo.

La tercera concepción es la dialéctico-materialista sobre el origen y desarrollo de la filosofía: esta revela ante todo su contenido universal, expresado en sus formas particulares y singulares. El conjunto de categorías elaboradas por la dialéctica materialista sobre la base de toda la herencia filosófica anterior, permite una mejor comprensión y explicación de la correlación existente entre el pensamiento filosófico universal y sus manifestaciones concretas en cada época y región del mundo. Especialmente las categorías de fenómeno, de lo singular, lo particular y lo universal, resultan de gran valor para el esclarecimiento del problema.

La concepción dialéctico-materialista de la filosofía sostiene también que ésta por su esencia es universal, desde su aparición hasta nuestros días, aun cuando en ocasiones se la quiere atribuir como un milagroso invento original de algunos milesios. Siempre mantendrá esa condición de universalidad pero expresada fenoménicamente en innumerables manifestaciones que de generación en generación y de pueblo a pueblo va constantemente conformando una imagen más acertada del mundo, independientemente de los desaciertos que a la larga quedan relegados por el progreso del conocimiento humano.

Algunos llegan a extrapolar la idea de la multivariedad de las manifestaciones de la filosofía y llegan a sostener que han existido y deben existir tantas filosofías como humanos dedicados a ella. El análisis científico de la historia de la filosofía revela lo infundado de tal argumentación. Incluso se ha sostenido el criterio de que la exagerada disolución de las escuelas de pensamiento que se ha producido en la filosofía contemporánea es síntoma de pluralismo, y por tanto de riqueza intelectual, cuando en verdad no 
es más que un síntoma de debilidad e insatisfacción ante las concepciones que hasta el momento han sido elaboradas para sentirse verdaderamente creador. ¿Tendrá el ser humano que elaborar siempre novedosas filosofías ante los problemas y situaciones nuevas o puede orientarse ante ellos sobre la base teórica y metodológica de alguna filosofía que ya ha demostrado cierta validez?, ¿sucederá en algún momento que, a semejanza del desarrollo de la ciencia, se irán unificando criterios y se arribará a verdades reconocidas por todos independientemente de la procedencia de los pensadores que las han revelado?, ¿acaso tendrá permanentemente la filosofía que estar marcada, como el arte y la literatura, básicamente, por el sello de las regiones en que se produce?

Aun cuando en la filosofía han confluido en mayor o menor medida otras formas de la conciencia social, como la ciencia, la religión, el arte, entre otras, aquella ha sabido mantener su especificidad, sus métodos propios, y demás, pero esto no significa que deba rechazar algunos elementos válidos y consustanciales a las restantes esferas de la actividad intelectual.

Si la filosofía aspira a ofrecer al ser humano respuestas acertadas a innumerables interrogantes que sean aceptables para cualquier circunstancia por su grado de universalidad y que sean objeto específico de las ciencias particulares, ya sean sociales o naturales, ¿̨por qué razón deberán continuar generándose nuevas escuelas de pensamiento diametralmente diferentes entre sí?, ¿es que acaso la heterogeneidad y multiplicidad del mundo fenoménico justifica eternamente tal diversidad filosófica?

La experiencia de los congresos mundiales de filosofía y otros eventos de esta índole demuestra que, no obstante la confrontación necesaria de criterios opuestos que se producen entre los representantes de las distintas corrientes filosóficas, la comunicación y el diálogo ofrecen como resultado el reconocimiento recíproco, por parte de los que se enfrentan, de las coincidencias en determinados aspectos, al menos a pesar de las divergencias sustanciales. ¿No serán estos los primeros síntomas del proceso de integración futura que, similar al ocurrido en la ciencia, le espera a la filosofía?

No hay razón para sostener que la tarea de las nuevas generaciones de filósofos consiste en elaborar nuevos "ismos" en lugar de contribuir a que se establezcan los nexos necesarios con el fin de que los pensadores de diferentes partes del mundo lleguen a una acertada interpretación dialéctico 
materialista de este y se propongan, consecuentemente, transformarlo en beneficio del ser humano.

Los defensores del marxismo orgánico han tratado de difundir la objetividad y el carácter científico de esta concepción y paulatinamente se ha logrado con éxito su difusión y desarrollo creador, vinculada a la transformación práctica de la realidad.

La cuestión no consiste en ofrecer, prejuiciadamente, respuestas al porqué y para qué filosofar, presuponiendo que sólo se hace, para simplemente defender una posición ideológica determinada (Hoyos, 1985, pp. 35-51) (59 $^{5}$ la cual por supuesto, está implícita en cualquier concepción filosófica, pero no se reduce a ella-, ni tampoco pensar que este planteamiento se hace desde una filosofía que no tiene su origen en la América Latina. En tanto se asuman tales posturas jamás se actuará en consecuencia con la concepción histórica universal de la esencia de la filosofía.

Mientras se pretenda redescubrir absolutamente la filosofía desde estas tierras latinoamericanas sucederá lo mismo que acontece cuando nos empeñamos en reinventar tecnologías ya perfeccionadas en países desarrollados y el abismo entre estos y nuestras economías se acrecienta en lugar de aminorarse.

Por otra parte, también en la medida en que se diluya la actividad filosófica en la mera interpretación de abstracciones estratosféricas, carentes del oxígeno vital e impregnado por el polvo, la humedad y la temperatura del suelo latinoamericano, tampoco tendrá sentido valedero encontrar respuestas aquí al porqué, y para qué filosofar.

59 En ocasiones aparecen interesantes posiciones ante el marxismo que van desde la reivindicación de la filosofía del marxismo, pero como crítica ideológica, hasta la negación de su contenido filosófico y reducirlo a una simple praxis política. Un ejemplo de la primera postura se aprecia cuando se afirma: “...es necesario conservar la filosofía en el marxismo. Pero no en la forma de una filosofía que legitime un materialismo científico, una ortonomía como se quiere ahora llamar al materialismo dialéctico. La función de la filosofía en el marxismo es la de ser crítica de ideologías". Hoyos, G. "Elementos para una interpretación filosófica del joven Marx". En In Memoriam Marx 1883-1983. CINEP, Bogotá, 1983, p. 61. Un ejemplo de la segunda postura aparece en la obra del mexicano Luis Salazar: Marxismo y filosofía: un horizonte polémico. UNAM, México, 1983. Para una crítica a estas posiciones véase Gerardo Ramos: "Política y concepción del mundo: antinomias del marxismo latinoamericano". En Revista Cubana de Ciencias Sociales, No. 17, La Habana, 1985, pp. 35-51. 
Si la esencia de la filosofía es universal, dejemos que cada una de sus expresiones fenoménicas en estas tierras contribuya a su descubrimiento (Baltodano, 1981). ${ }^{60}$ Es bueno recordar que las esencias no existen jamás de forma pura, por lo que resulta estéril también ir en busca de la filosofía pura. La filosofía siempre existirá a través de las formas particulares que adoptará en cada momento y en cada país con rasgos sui géneris, pero tales rasgos no determinan fatalmente su contenido. Ellos son factores que coadyuvan a la mayor o menor asimilación por un pueblo en su idioma propio de los avances alcanzados por el pensamiento filosófico universal.

La dialéctica materialista demuestra que lo único es irrepetible, se da una sola vez, pero no existe por sí y para sí solamente (Bagú, 1988, pp. 56-57) . ${ }^{61}$

Las filosofías que han prendido en América Latina independientemente de su procedencia, tampoco escapan a esta necesidad. Ellas han poseído, y así lo expresan, rasgos comunes no solo con las ideas de sus reconocidos creadores, sino también semejanzas marcadas con las que provienen de otros pensadores, tanto de este continente como de los más lejanos, ¿resulta esto mera coincidencia o es expresión de la determinación dialéctica de la que no escapa ni la propia filosofía?

60 Un intento por contribuir al redescubrimiento de la validez de las tesis fundamentales del marxismo, a partir de las enseñanzas de Mariátegui estudiando la realidad peruana, se aprecia en Baltodano Azabache, Víctor. Los pensamientos básicos del materialismo histórico y su desarrollo en el Perú. Editorial Universitaria, Universidad Nacional de Trujillo, Perú, 1981.

61 En un profundo análisis dialéctico del marxista argentino Sergio Bagú planteaba al respecto: "No hay una teoría social válida en Europa e inaplicable en América Latina. Pero en la búsqueda de la lógica global de los procesos sociales - el descubrimiento de las leyes históricas como se decía en el siglo XIX - se van alcanzando escalas diferentes de generalización. Si una lógica aplicable a la realidad europea es parcialmente inaplicable para descifrar la realidad latinoamericana es probable que pueda elevarse a un nivel mayor de generalización que permita explicar satisfactoriamente tanto la realidad europea como la latinoamericana. No se trata de un luego de ingenio, sino del proceso mismo de construcción teórica. EI mejor conocimiento de la realidad latinoamericana permite comprender mejor la realidad europea. En otras palabras, cuando se llega a una lógica igualmente satisfactoria para comprender lo europeo y lo latinoamericano, se ha descubierto cómo comprender mucho más profundamente en particular tanto una realidad como la otra." Bagú, S. "Valor interpretativo de la obra de Marx y Engels aplicable a la realidad de América Latina”. En Dialéctica. No. 19, Puebla, julio de 1988, pp. 56-57. 
Tales parecidos y aproximaciones constituyen particularidades que es imprescindible delimitar en cualquier investigación histórico-filosófica. Por supuesto que la misión de la ciencia histórica sobre la trayectoria del pensamiento filosófico latinoamericano no puede limitarse al establecimiento sencillamente de comparación o analogías. Ella tiene que revelar y explicar todas y cada una de las determinaciones de su especificidad, su mayor o menor originalidad, su correspondencia con las exigencias epocales en todos los órdenes, entre otras. Pero en este desempeño irá desentrañando todos los puntos y las diferencias con el pensamiento de otras regiones y así reconocerá que sus respuestas al porqué y al para qué filosofar no son tan disímiles a las ofrecidas por otros.

¿Como consecuencia de qué vale atizar las diferencias entre las formas del filosofar en distintas regiones del mundo?, ¿ de qué modo se beneficia el desarrollo del pensamiento filosófico latinoamericano? Limitándolo simplemente, o bien a la tarea de servir de traductor de lo que piensan otros en la afanosa búsqueda de nuevas metafísicas que evaden las condiciones del latinoamericano, para el que se supone deben ser útiles; o bien cerrando el círculo de la reflexión filosófica a los problemas del latinoamericano, su ser, su circunstancia, entre otras, ignorando que la causa de tal situación rompe las fronteras geográficas de este continente y se encuentra en las diferentes formas de explotación del "hombre por el hombre" que la historia no recoge solamente como acaecidas en un pasado remoto que se mide por siglos, sino en uno tan reciente que nos pisa los talones y debe ser medido en horas y minutos.

A nuestro juicio, el filosofar en América Latina encontrará mejor respuesta a sus por qué y para qué en la posición de la dialéctica materialista que, reconociendo las diferencias, las formas singulares y particulares de manifestarse, a la conclusión de que filosofías han existido y podrán existir muchas, pero no todas podrán ser poseedoras de verdades diferentes sobre un mismo problema y excluirse recíprocamente. Una vez más la lógica formal pone de manifiesto sus limitaciones para explicar el carácter contradictorio del desarrollo, en este caso, de la propia filosofía y se hace imprescindible acudir a la lógica dialéctica para comprender los momentos de singularidad, particularidad y universalidad que se dan en cada manifestación del pensamiento filosófico latinoamericano. 
Solo así surgirán suficientes motivaciones para, ni sentirse aislado de la fuente terrenal que alimenta todo filosofar, ni al margen tampoco de las grandes elaboraciones teóricas que ha ido desarrollando la humanidad paulatinamente y que por encima de las fronteras ponen al ser humano en contacto con nuevas verdades propiamente. La toma de conciencia sobre el porqué y el para qué filosofar en América Latina coincidirá entonces plenamente con la marcha del progreso humano y los frutos de su labor podrán alimentar no solo a los latinoamericanos, tan necesitados de teorías consecuentes y praxis realizadoras, sino a todos los seres humanos que en cualquier parte esperan algo más que meras palabras de la filosofía. 

Capítulo IV

Biblioteca

(Nㅗ COLOMBIANA 
